\title{
PITUITARY TUMOR APOPLEXY
}

\author{
Claudia V. Chang', Andre C. Felicio², Andrea Cecilia Toscanini', \\ Manoel Jacobsen Teixeira ${ }^{3}$, Malebranche Berardo Carneiro da Cunha-Neto ${ }^{1}$
}

\begin{abstract}
Pituitary tumor apoplexy is a medical emergency due to acute infarction or hemorrhage in the pituitary gland. In this review, the authors discuss the sellar anatomy, the pituitary gland and adenomas' vascularization and the general aspects of the syndrome such as its ethiopatogenesis, predisposing factors, clinical features, treatment and prognosis.
\end{abstract}

KEY WORDS: pituitary tumor apoplexy, pituitary, pituitary adenomas.

\section{Apoplexia em tumor hipofisário}

Resumo - A apoplexia em tumor hipofisário é uma emergência médica decorrente do infarto agudo ou hemorrágico na glândula hipófise. Nesta revisão os autores discutem a anatomia da região selar, a vascularização da hipófise e adenomas hipofisários, e demais aspectos da síndrome como etiopatogenia, fatores predisponentes, quadro clínico, tratamento e prognóstico.

PALAVRAS-CHAVE: apoplexia hipofisária, hipófise, adenoma hipofisário.

Pituitary apoplexy is a potentially life-threatening disorder due to acute ischemic infarction or hemorrhage of the pituitary gland. The main clinical features of this syndrome are headache, nausea, vomiting, visual impairment, altered mental status, and even coma ${ }^{1-4}$. As the primary event involves the adenoma, the syndrome should be referred to as pituitary tumor apoplexy and not as pituitary apoplexy $y^{5}$. Notwithstanding pituitary apoplexy occurs within pituitary adenomas, it may also occur in non-adenomatous or even the normal pituitary gland ${ }^{6}$, especially during pregnancy.

Although the "subclinical pituitary apoplexy"7-9 terminology is widely used to describe anatomophatological evidence of asymptomatic pituitary ischemia or hemorrhage, it is meaningful to note that pituitary apoplexy is a clinical syndrome rather than an anatomopathological definition ${ }^{10,11}$.

\section{ANATOMY OF THE SELLAR REGION}

The pituitary gland is circumscribed by the sphenoid bone among its whole surface and enclosed with the diaphragma sellae. It relies on the sella turcica under the hypothalamus and optic chiasma. In the adult, it measures approximately $12 \times 9 \times 6 \mathrm{~mm}$ diameters and weights $0,6 \mathrm{~g}$, and during pregnancy its volume may double. The pitu- itary gland can be divided into two major parts: one situated at the anterior site corresponding to $80 \%$ of the gland (adeno-pituitary) and the remaining $20 \%$ on the posterior site of the gland (neuro-pituitary) ${ }^{12}$.

\section{VASCULARIZATION OF HYPOTHALAMUS AND PITUITARY GLAND}

There are up to ten portal pituitary vessels that originate dorsally at capillaries from the median eminence. These vessels move alongside the ventral surface of the anterior pituitary stalk and drain to the adeno-pituitary making anastomosis with the neuro-pituitary capillaries. The circulation is predominantly through hypothalamus to pituitary gland and allows pituitary to be the most irrigated region of the body $(0.8 \mathrm{ml} / \mathrm{g} / \mathrm{min})$. It is still not known whether the anterior lobe of the pituitary gland receives its blood supply exclusively from the portal circulation or if there is some additional arterial blood supply $^{5}$. It is believed that 70 to $90 \%$ of adeno-pituitary irrigation comes from major portal vessels and the remaining from lesser ones. Another controversial issue is the penetration of loral artery to the anterior lobe passing away the infundibular stem, and providing arterial blood to pituitary cells. A further potential source of direct arteri-

\footnotetext{
'Unidade de Neuroendocrinologia da Divisão de Neurocirurgia do Hospital das Clínicas da Faculdade de Medicina da Universidade de São Paulo, São Paulo SP, Brazil (HC-FMUSP); ${ }^{2}$ Departamento de Neurologia da Universidade Federal de São Paulo, São Paulo SP, Brazil; ${ }^{3}$ Departamento de Neurologia do HC-FMUSP.
}

Received 2 September 2008, received in final form 15 December 2008. Accepted 9 March 2009. 
al supply for the adeno-pituitary could be capsular arteries, originated from inferior pituitary arteries which are branches from the internal carotid artery. On the other side, venous drainage takes place within adjacent venous sinus to the jugular veins ${ }^{12}$.

To sum up, pituitary gland is one of the greatest irrigated structures of our organism with a complex vascular system ${ }^{13}$, and therefore pituitary adenomas have a 5.4 greater chance to bleed than any other brain tumor ${ }^{14}$.

\section{VASCULARIZATION OF PITUITARY ADENOMAS}

The number and size of tumoral vessels are variable. Generally they are lesser than the normal pituitary vessels and are divided into irregular islets. Under electronic microscopy they have incomplete maturation, low fenestration, and fragmented basal membranes with sized perivascular spaces filled with plasmatic proteins or red cells ${ }^{15,16}$. Adenomas receive a mixed arterial or portal blood, but in contrast to the normal pituitary gland, the arterial source is generally more dominant in pituitary adenomas ${ }^{17}$.

The angiographic characteristic of tumoral vessels that supply adenomas implies that they come from the inferior pituitary artery, and are under the influence of systemic arterial pressure ${ }^{12,17}$.

\section{ETIOPATHOLOGY}

The etiopathology of pituitary apoplexy is still a matter of debate. Some authors believe pituitary apoplexy occurs due to rapid tumoral growth that outstrips arterial supply ${ }^{18-20}$. It is uncertain whether the pathological process is a primary hemorrhage or whether the event is really a hemorrhagic infarction. The size of the adenoma appears to be a major factor ${ }^{21}$, but it is known that even smaller adenomas can bleed. Another rationale for pituitary apoplexy could be the tumoral tissue growing inside the narrow space situated between the pituitary stalk and diaphragma sellae leading to constriction of the thin vascular net adjacent to the stalk, and finally ischemia, necrosis and hemorrhage on the anterior lobe and tumoral tissue ${ }^{22}$. Taking into account that the adenoma is supplied by the inferior pituitary artery, the compression of the superior pituitary artery and its branches against the diaphragma sellae could lead to ischemia of the adenopituitary and not the adenoma. If this is true the hemorrhage would begin within the normal pituitary gland instead of the adenoma itself $f^{22}$.

The intentional (surgical) occlusion in animals or humans of portal pituitary vessels leads to ischemic infarction and not hemorrhage. The process begins with the volume reduction of acinar cells and its splitting from the basal membranes, culminating to necrosis ${ }^{23}$. Patients who have tumor infarction have generally less severe clinical symptoms and longer course before presenting for medi- cal care than those who have hemorrhage or hemorrhagic infarction of the adenoma ${ }^{24}$.

The hypothesis of tumoral "intrinsic" factors ending to hemorrhage is also suggested. There is a statistically significant relationship between the aggressive and invasive tumoral behavior and hemorrhage ${ }^{11,23}$. The role of vasospasm was also implicated on the etiophatology of pituitary infarction. Intracranial aneurisms are more often associated to pituitary adenomas than in the general population or with other brain tumors ${ }^{5,12}$. Additionally, pituitary adenomas bleed much more than any other central nervous system tumor. Thus, one might speculate of an "intrinsic" factor such as a kind of tumoral-vasculopathy underlying the mechanism of aneurism development and pituitary hemorrhage ${ }^{25}$.

\section{PREDISPOSING FACTORS}

Numerous conditions have been linked to pituitary apoplexy but in the majority of cases it happens without any predisposing factor but pituitary adenoma ${ }^{5,25}$. The main predisposing factors associated to pituitary apoplexy ( $25 \%$ of cases) are: medication (bromocriptine and cabergoline $)^{26-28}$, radiotherapy ${ }^{29}$, pituitary function tests $^{30,31}$, diabetes mellitus, trauma, thrombocytopenia or recent surgery ${ }^{32-36}$. High blood pressure is also considered as a risk factor for pituitary apoplexy although this association is not always seen ${ }^{1,6}$.

The prevalence of apoplexy according to different subtypes of pituitary tumors is homogeneous with a small trend for non-functioning adenomas and prolactinomas to develop apoplexy. GH-, ACTH-, TSH-, and gonadotrophin-secreting tumors shares similar prevalence ${ }^{5,21}$. It is believed that between non-functioning adenomas and prolactinomas the prevalence is slightly greater in the former, perhaps because the peak prevalence of pituitary apoplexy is similar to that of non-functioning adenomas, which is the fiftieth decade of life ${ }^{12}$.

\section{CLINICAL FEATURES}

The diagnosis of pituitary tumor apoplexy is frequently missed because, in addition to its relative rarity, the existence of an adenoma is not often suspect at the time time of ictus. Headache is the major symptom of pituitary apoplexy in patients without altered mental status, and it can have sudden onset with severe pain. Occasionally it is generalized, but most often retro-orbitary or peri-orbitary. Headache is not necessarily associated with sub-arachnoid hemorrhage or means tumoral growth beyond the sella turcica. The potential mechanisms underlying headache in pituitary apoplexy are meningeal irritation, dura-mater compression, enlargement of sella turcica walls, or involvement of the superior division of the trigeminal nerve inside cavernous sinus ${ }^{37}$. 
Altered visual field or visual acuity means involvement of the optic nerves, chiasma, or optic tracts. Motor ocular nerves (III, IV, and VI) are vulnerable at the cavernous sinus and therefore in the majority of patients that do not show altered mental status headache is associated with diplopia,12. The medial aspect of the cavernous sinus corresponds to the lateral aspect of the pituitary fossa and for that reason an acute hemorrhage or necrosis within this region can shift the oculomotor nerves. Thus, visual impairment and the presence of motor ocular involvement do not necessarily means supra or para-sellar growth of pituitary tumors. Ipsilateral mydriasis and ptosis are owing to IIIrd nerve involvement. Facial numbness may also take place due to the Vth nerve first division involvement ${ }^{12}$.

Altered mental status is the most severe neurological finding in patients with pituitary apoplexy ${ }^{5}$. Its mechanism remains elusive and might be related to sub-arachnoid hemorrhage, increased intracranial pressure, obstructive hydrocephalus, adrenal insufficiency leading to arterial hypotension and hypoglycemia, and hypothalamic compression.

Nausea and vomiting may occur due to adrenal insufficiency, meningeal irritation, and hypothalamic dysfunction or raised intracranial pressure. Neck stiffness is observed in patients with pituitary apoplexy and should raise the attention for sub-arachnoid hemorrhage ${ }^{3}$.

Focal signs such as loss of muscle strength or aphasia are less common and are attributed to internal carotid artery compression or vasospasm ${ }^{6}$.

The majority of patients do not have the diagnosis of pituitary adenoma at the time of pituitary apoplexy, but a retrospective and careful evaluation of these patients can show previous evidence of endocrine dysfunction. The most clinically important deficit is that of ACTH because it leads to acute glucocorticoid insufficiency occurring at the time of severe physical stress. The majority of patients present with, at least, partial hypopituitarism. Reviewing a series of patients that had pituitary apoplexy, Veldhuis and Hammond ${ }^{38}$ found multiple adeno-pituitary hormon-

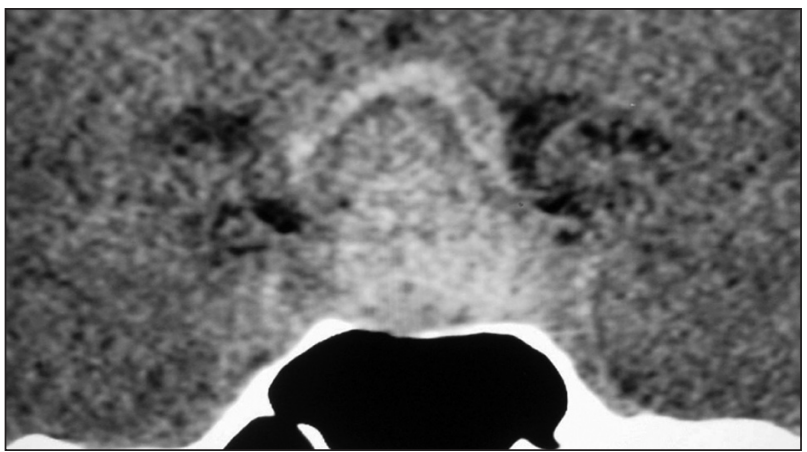

Fig 1. Note on this sellar computer tomography (coronal view) the adenoma located at the sella turcica with an acute hemorrhage seen as an hyperdense lesion. al deficiencies such as: GH deficit (88\%), ACTH hyposecretion (66\%), hypothyroidism (42\%) and hypogonadothrofic hypogonadism (85\%).

Transient diabetes insipidus is not a common feature of pituitary apoplexy and is reported in only $4 \%$ of cases ${ }^{39}$. Rarely, inappropriate ADH secretion occurs, perhaps due to sparing of neuro-pituitary or pituitary stalk ${ }^{10}$.

\section{NEUROIMAGING}

Although it is in disuse, plain radiography of the skull is a quick and inexpensive method for evaluating pituitary apoplexy showing enlargement of the pituitary fossa and destruction of sellar dorsum ${ }^{4}$. Rarely, a fracture of sellar dorsum is seen, and this is considered an specific sign of pituitary apoplexy. A normal plain radiography does not exclude pituitary apoplexy.

A recent hemorrhage can appear as a single or multiple lesion with hyperdense sign on brain computer tomography (CT) (Fig 1) and no one or tiny contrast enhancemet ${ }^{4,12,40}$. On subsequent days after hemorrhage a progressive reduction of lesion hyperdensity occurs and after iodine contrast injection a peripheral ring is seen around the lesion ${ }^{22}$. At this time (approximately four days after bleeding) the hemorrhage can be misinterpreted as cystic degeneration, abscess, or local infarction, since all these conditions have lower density sign on scans ${ }^{25}$. Brain CT can also demonstrate sub-arachnoid hemorrhage and whether there is involvement of brain and ventricles. Sometimes the differentiation between a non-complicated and a bleeding adenoma can be difficult or even impossible because the observed densities on CT may be variable and there is no hallmark to differentiate both conditions. Occasionally, serial scans are recommended but it should

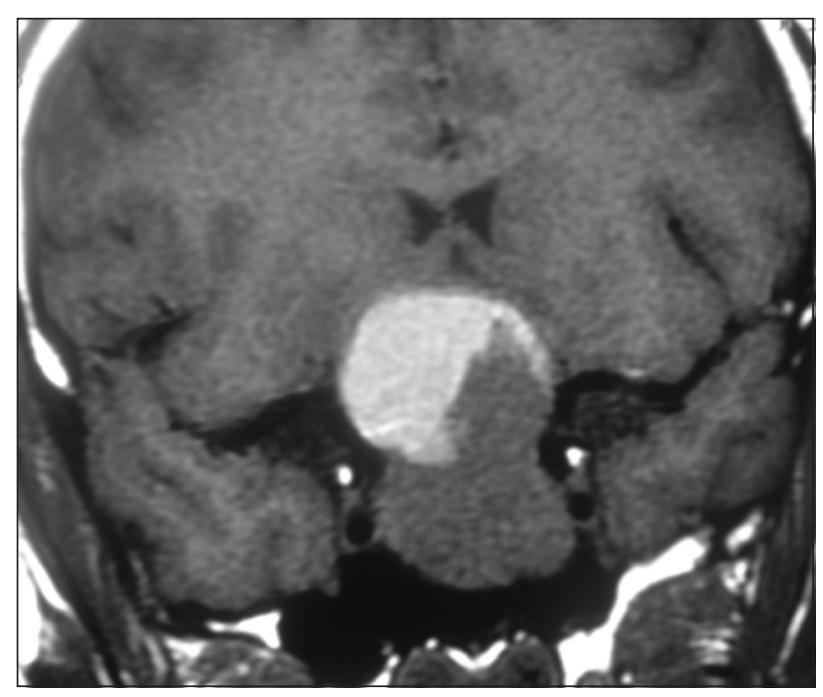

Fig 2. Note on this T7-weighted magnetic resonance imaging (coronal view) a sellar and suprasellar mass (adenoma) with a hyperintense chronic hemorrhage. 
be taken into consideration that the first three days after pituitary apoplexy are the best period for CT handling ${ }^{34}$.

Unless specific techniques of imaging acquisition are obtained (diffusion-weighted) ${ }^{4}$ brain magnetic resonance imaging (MRI) is less efficient than CT in the acute stage of pituitary apoplexy. On the sub-acute and chronic stages of pituitary apoplexy brain MRI is considerably better than $\mathrm{CT}^{25}$. One of the advantages of MRI is the possibility of estimating the onset of bleeding. In the acute stage of pituitary apoplexy (first seven days) it is seen on MRI characteristic hypo- or isointense lesions on $\mathrm{T}_{1}$ - and $\mathrm{T}_{2}$-weigthed images; between seven to fourteen days on the sub-acute stage there is marginal signal reinforcement although the hematoma core remains isointense; on the chronic stage there is an overall increase on $\mathrm{T}_{1}$ - and $\mathrm{T}_{2}$ - signal (Fig 2). The hyperintense lesion on MRI may last much longer than CT (up to one year after pituitary apoplexy) . $^{12}$

Hypersignal on $\mathrm{T}_{1}$-weighted sequences is seen on hemorrhagic tissues, fat, and lesions with high protein or melanin content. Thus, intra-sellar tumors that may present with $\mathrm{T}_{1}$ hyperintense signal are craniopharingiomas, lipomas, dermoid cysts, metastatic melanomas or any other hemorrhagic tumor ${ }^{34}$. Clinical characteristics together with other brain MRI abnormalities may help to elucidate diagnosis. Unlike pituitary apoplexy on $\mathrm{T}_{2}$-weighted images sub-acute or chronic hemorrhagic tissues, lipomas, dermoid cysts, and melanomas are often hypointense. Craniopharingiomas may be hyperintense either on $T_{1}$ or $T_{2}$ images due to its high protein content within cysts, becoming a difficult differential diagnosis with pituitary tumors that bleed or show necrosis ${ }^{12}$. Craniopharingiomas, lipomas, and dermoid cysts generally presents with slow clinical deficits opposing to hemorrhagic or metastatic lesions that presents with acute neurological manifestations.

Angiography may also be helpful in the management of pituitary apoplexy as it shows the presence or absence of concomitant aneurism ( $7 \%$ of cases), and vasospasm. If there are no associated abnormalities the tumoral mass can be seen with contrast enhancement. Angiography is obligatory especially in patients with neck stiffness accompanied to focal neurological signs or inconclusive CT or MRI scans ${ }^{4}$.

\section{DIFFERENTIAL DIAGNOSIS}

Clinical conditions frequently misdiagnosed as pituitary apoplexy are sub-arachnoid hemorrhage due to ruptured intracranial aneurism and meningitis. Other diseases that may share similar clinical characteristics are basilar artery occlusion, hypertensive encephalopathy, brain abscess or cyst, cavernous sinus thrombosis, intracerebral hematoma, encephalitis, retrobulbar neuritis, temporal arteritis, and ophthalmoplegic migraine. Some key points described below are recommended to elucidate diagnosis ${ }^{1,4,41}$.
Clinical presentation of pituitary apoplexy may resemble ruptured intracranial aneurism due to sudden onset headache, ocular palsy and altered mental status. Prompt diagnosis of pituitary apoplexy is important in patients with ocular palsy (ophthalmoplegia is more likely to be seen in patients with tumor apoplexy) because decompressive surgery of the optic pathway may alleviate symptoms. In patients with aneurismal subarachnoid hemorrhage the symptoms develop more rapidly after the onset of headache than would be expected in patients with tumor apoplexy $y^{5}$. Diagnostic differentiation using only clinical data is not reliable. Frequently time lag between headache and onset of altered mental status is shorter on subarachnoid hemorrhage than on pituitary apoplexy. Recurrent bleeding may occur not only due to aneurism but pituitary apoplexy as well.

In the past, cerebrospinal fluid (CSF) red cell counting took great interest for the differentiation between aneurismatic or pituitary sub-arachnoid hemorrhage. Altered mental status together with small red cell counting on CSF was ordinarily attributed to pituitary apoplexy. Higher red cell counting however may be seen in pituitary apoplexy especially if there is rupture of diaphragma sellae. Currently, CSF is used only to detect if there is concomitant sub-arachnoid hemorrhage not seen on CT but not as a tool for differentiating pituitary apoplexy from bleeding aneurisms ${ }^{32}$.

\section{TREATMENT}

Treatment of pituitary apoplexy in the acute stage is still controversial with regard to surgical intervention ${ }^{7,42}$. Regardless the severity of clinical presentation the course of pituitary apoplexy is unpredictable. The choice for conservative or surgical interventions is generally individually assessed. Untreated patients with apoplexy have higher morbidity and mortality. Altered consciousness, hypopituitarism, and intercurrent illness account for the increased mortality of untreated patients.

If there is altered mental status without recovery after neurological and endocrinological treatment surgical intervention is required. Visual field and visual acuity impairment are also better assessed with surgical decompression after supportive clinical management. Although stereotactic aspiration is currently ongoing, open surgery via trans-sphenoidal allows a better chance for complete tumor removal. The stereotactic method however may be required for unstable or high risk patients in spite of open surgical access. Craniotomy is considered in cases of nonaired sphenoidal sinus, small sella turcica, great supra-sellar mass, and short diaphragma sellae ${ }^{12,23}$.

Thus, trans-sphenoidal via is the procedure of choice for bleeding pituitary adenomas. Tumors are generally necrotic or hemorrhagic and easy to aspirate and surgery 
can be performed without dissection of chiasmatic cisterna and lower risk of damaging the superior irrigation of optic chiasm. This is relevant since the inferior blood supply for optic chiasm is already affected due to adenoma or its expansion due to apoplexy ${ }^{7}$.

In cases of internal artery carotid compression surgery is urgently required and cannot be postponed unless brain infarction is already evident. We believe treatment of pregnant women with pituitary apoplexy should be identically managed ${ }^{12}$.

Ocular palsy has to be evaluated with caution and it is recommended that a conservative procedure is better than an invasive one in patients with small deficits or with recovering symptoms. However early detection of ocular palsy and severe involvement of extra-ocular muscles should be surgically and promptly assessed ${ }^{5}$.

As soon as diagnosis of pituitary apoplexy is made and after collecting blood sample for hematological, biochemistry, and hormonal analysis, glucocorticoids should be administered in supraphysiological doses to serve not only as replacement for endogenous hormone deficiency but also to help control the effect of edema. Dose recommended is between 8 to $16 \mathrm{mg}$ dexametasone, or hydrocortisone $50 \mathrm{mg}$ intravenously every 6 hours during the first 48 hours ${ }^{4,5}$. Occasionally, patients are clinically or biochemically hypothyroid at presentation. This aspect of endocrine function should be recognized before surgical intervention. However, hypothyroidism is not a contraindication for surgery. Unless the hypothyroidism is severe, the surgical decompression need not be delayed, but it is important to avoid medications and procedures that are particularly deleterious and that can potentially worsen clinical symptoms, such as depressants and narcotics ${ }^{5}$.

\section{NEUROSURGICAL OUTCOME}

Unless neurosurgery is postponed the results of microsurgery decompression after pituitary apoplexy are satisfactory. The degree of visual field recovery depends much on the time for neurosurgery approach than the severity of visual deficit. It was seen that surgery within one week after pituitary apoplexy lead to a greater visual acuity recovery than patients operated later ${ }^{37}$. The likelihood for visual acuity to recover is lower than ocular palsy.

It is important to note that endocrinological followup after surgery is necessary since many patients need hormonal replacement for a long-term basis. Patients with sub-acute or chronic pituitary apoplexy should have serial (control) neuroimaging and interestingly it is not uncommon to see tumor reduction or even tumor vanishing due to apoplexy or necrosis avoiding unnecessary neurosurgical removal.

In conclusion, although pituitary apoplexy is an uncommon complication of pituitary tumors it should be recognized as a neuroendocrinological and neurosurgical emergence that requires prompt diagnosis and treatment individualizing each subject to direct for conservative or more invasive therapies.

\section{REFERENCES}

1. Randeva HS, Schoebel J, Byrnet J, Esiri M, Adams CB, Wass JA. Classical pituitary apoplexy: clinical features, management and outcome. Clin Endocrinol 1999;51:181-188.

2. Sibal L, Ball SG, Connolly V, et al . Pituitary apoplexy: a review of clinical presentation, management and outcome in 45 cases. Pituitary 2004;7:157-163.

3. Elsässer Imboden PN, De Tribolet N, Lobrinus A, et al. Apoplexy in pituitary macroadenoma: eight patients presenting in 12 months. Medicine 2005;84:188-196.

4. Dubuisson AS, Beckers A, Stevenaert A. Classical pituitary tumour apoplexy: clinical features, management and outcomes in a series of 24 patients. Clin Neurol Neurosurg 2007;109:63-70.

5. Nawar RN, AbdelMannan D, Selma WR, Arafah BM. Pituitary tumor apoplexy: a review. J Intensive Care Med 2008;23:75-89.

6. Biousse V, Newman NJ, Oyesiku NM. Precipitating factors in pituitary apoplexy. J Neurol Neurosurg Psychiatry 2001;71:542-545.

7. Onesti ST, Wisniewski T, Post KD. Clinical versus subclinical pituitary apoplexy: presentation, surgical management, and outcome in 21 patients. Neurosurgery 1990;26: 980-986.

8. Miranda M, Barros L, Knopfelmacher M, et al. Pituitary apoplexy followed by endocrine remission. Report of two cases. Arq Neuropsiquiatr 1998;56:449-452.

9. Pinheiro MM, Cukiert A, Salgado LR, et al. Subclinical apoplexy in pituitary tumors. Arq Neuropsiquiatr 1999;57:74-77.

10. Fraioli B, Esposito V, Palma L, Cantore G. Hemorrhagic pituitary adenomas: clinicopathological features and surgical treatment. Neurosurgery 1990;27:741-747.

11. McFadzean RM, Doyle D, Rampling R, Teasdale E, Teasdale G. Pituitary apoplexy and its effect on vision. Neurosurgery 1991;29:669-675.

12. Cunha-Neto MBC, Musolino NRC, Toscanini AC. Síndrome da sela vazia e apoplexia hipofisária. In Saad MJA, Maciel RMB, Mendonça BB (Eds). Endocrinologia. São Paulo: Editora Atheneu, 2007:47-62.

13. Reid RL, Quigley ME, Yen SS. Pituitary apoplexy. A review. Arch Neurol 1985;42:712-719.

14. Wakai S, Fukushima T, Teramoto A, Sano K. Pituitary apoplexy: its incidence and clinical significance. J Neurosurg 1981;55:187-193.

15. Hirano A, Tomiyasu U, Zimmerman HM. The fine structure of blood vessels in chromophobe adenoma. Acta Neuropathol (Berl) 1972;22:200-207.

16. Schechter J. Ultrastructural changes in the capillary bed of human pituitary tumors. Am J Pathol 1972;6:333-342.

17. Baker HL Jr. The angiographic delineation of sellar and parasellar masses. Radiology 1972;104:67-78.

18. Brougham M, Heusner AP, Adams RD. Acute degenerative 
changes in adenomas of the pituitary body - with special reference to pituitary apoplexy. J Neurosurg 1950;7:421-439.

19. Uihlein A, Balfour WM, Donovan PF. Acute haemorrhage into pituitary adenomas. J Neurosurg 1957;14:140-151.

20. Wakai S, Yamakawa K, Manaka S, Takakura K. Spontaneous Intracranial hemorrhage caused by brain tumor: its incidence and clinical significance. Neurosurgery 1982;10:437-444.

21. Arafah BM, Ybarra J, Tarr RW, Madhun ZT, Selman WR. Pituitary tumor apoplexy: pathophysiology, clinical manifestations and management. J Intensive Care Med 1997;12:123-134.

22. Rovit RL, Fein JM. Pituitary apoplexy: a review and reappraisal. J Neurosurg 1972;37:280-288.

23. Fraioli B, Esposito V, Palma L, Cantore G. Hemorrhagic pituitary adenomas: clinicopathological features and surgical treatment. Neurosurgery 1990;27:741-747.

24. Semple PL, De Villiers JC, Bowen RM, Lopes MB, Laws ER. Pituitary apoplexy: do histological features influence the clinical presentation and outcome? J Neurosurg 2006;104:931-937.

25. Cardoso ER, Peterson EW. Pituitary apoplexy: a review. Neurosurgery 1984;14:363-373.

26. Shirataki K, Chihara K, Shibata Y, Tamaki N, Matsumoto S, Fugita T. Pituitary apoplexy manifested during a bromocriptine test in a patient with a growth hormone- and prolactina-producing pituitary adenoma. Neurosurgery 1988; 23:395-398.

27. Vella A, Young Jr WF. Pituitary apoplexy. The Endocrinologist 2001;11:282-288.

28. Knoepfelmacher M, Gomes MC, Melo ME, Mendonça BB. Pituitary apoplexy during therapy with carbegoline in an adolescent male with prolactin-secreting macroadenoma. Pituitary 2004;7:83-87.

29. Ostrov SG, Quencer RM, Hoffman JC, Davis PC, Hasso NA, David NJ. Hemorrhage within pituitary adenomas: how often associated with pituitary apoplexy syndrome? AJR Am J Roentgenol 1989;153:153-160.

30. Miranda M, Barros L, Knopfelmacher M, et al. Apoplexia pituitária seguida de remissão endócrina relato de dois casos. Arq Neuropsiquiatr 1998;56:449-452.
31. Dometas HS, Selcuklu A, Colak R, Unluhizarci K, Bayram F, Kelestimur F. Pituitary apoplexy probably due to TRH and GnRH stimulation tests in a patient with acromegaly. J Endocrinol Invest 1999;23:698-700.

32. Bonicki W, Kasperkik-Zluska A, Koszewski W, Zgliczynski W, Wilawski J. Pituitary apoplexy: endocrine, surgical and oncological emergency. Incidence, clinical course and treatment with reference to 799 cases of pituitary adenomas. Acta Neurochir 1993;120:118-123.

33. Bhattacharrya A, Tymms DJ, Naqvi N. Asymptomatic pituitary apoplexy after aortocoronary bypass surgery. Int J Clin Pract 1999;53:394-395.

34. Motta LA, Mello PA, Lacerda CM, Neto AP, Motta LD, Filho MF. Pituitary apoplexy. Clinical course, endocrine evaluations and treatment analysis. J Neurosurg Sci 1999;43;25-36.

35. Wongpraparut N, Pleanboonlers N, Suwattee P, et al. Pituitary apoplexy in a patient with acute myeloid leukaemia and thrombocytopenia. Pituitary 2000;3:113-116.

36. Mukhida K, Kolyvas G. Pituitary apoplexy following cardiac surgery. Can J Neurol Sci 2007;34:390-393.

37. Bills DC, Meyer FB, Laws ER, et al. A retrospective analysis of pituitary apoplexy. Neurosurgery 1993;33:602-609.

38. Veldhuis JD, Hammond JM. Endocrine function after spontaneous infarction of the human pituitary: report, review and reappraisal. Endocr Rev 1980;1:100-107.

39. dos Santos Silva CM, Lima GA, Machado EO, Van Haute FR, Gadelha MR. Transient central diabetes insipidus followed by pituitary apoplexy treated in a conservative way. Arq Neuropsiquiatr 2008;66:415-417.

40. Post MJ, David NJ, Glaser JS, Safran A. Pituitary apoplexy: diagnosis by computed tomography. Radiology 1980;134:665-670

41. Kleinschmidt-DeMasters BK, Lillehei KO, Stears JC. The pathological, surgical and MR spectrum of Rathke cleft cysts. Surg Neurol 1995;44:19-27.

42. Maccagnan P, Macedo CL, Kayath MJ, Nogueira RG, Abucham J. Conservative management of pituitary apoplexy: a prospective study. J Clin Endocrinol Metab 1995;80:2190-2197. 